\title{
An Internet-based blood pressure monitoring system for patients
}

\begin{abstract}
We developed a personal blood pressure monitoring system for patients with hypertension or hypotension. The system can be used to measure a patient's blood pressure at home and to transmit the data automatically to a hospital database via the Internet. The accuracy of blood pressure readings using the system was assessed by comparison with readings from a standard digital sphygmomanometer in four subjects. The measurement error for the systolic readings was $1.7-2.7 \%$ and for the diastolic readings $2.7-3.2 \%$. The system therefore appears to be a promising means of assessing blood pressure remotely.
\end{abstract}

Keyword: Blood pressure; Hypertension; Hypotension; Internet; Telemedicine; Blood pressure determination 